\section{Reply to Ormerod}

Journal of the Operational Research Society (2003) 54, 324. doi:10.1057/palgrave.jors.2601487

I'd like first of all to welcome Richard Ormerod's engagement with the issues raised in my recent paper. ${ }^{1}$ I would however like to make a number of observations on his discussion, and in particular to note the curious difference in his mode of discussion in relation to (i) deconstruction and (ii) re-evaluation counselling or co-counselling.

First, a point of clarification in relation to the curious opposition he sets up in his first two paragraphs on deconstruction: 'If Taket is merely borrowing' (para 1), and then 'If however, we take it that Taket is serious about deconstruction theory' (para 2). Well Richard, let me clarify, I am both borrowing from and serious about deconstruction theory (and practice).

In the paper, I treat speech as a text (the 'yet to be written down' is not relevant for my purposes). What the participants in the example I gave were doing was creating and deconstructing a text in the course of a discussion. What was going on was both intentional (on my part) and unintentional (on the other participants' parts) use of deconstructive strategies. Ormerod amplifies and identifies different possible sources of texts, and illustrates some further possibilities for use, including training all participants in a group process in deconstruction. I look forward to seeing him write about how he develops his ideas in his practice.

In contrast to his readiness to engage with deconstruction, it seems that Ormerod cannot move fast enough away from co-counselling, and his 'argument' here is curiously free or any reference to his experience or anyone else's, or of any theoretical basis; instead it is based on purely speculative statements about what 'some psychologists' might think or dispute. He presents no evidence at all. There is much more I could say about the differences and similarities between the therapies Ormerod mentions and co-counselling than I did in the paper, and for reasons of length I will not do that here. I agree with Ormerod that there are indeed ethical issues involved in facilitation, as in every part of OR practice, and indeed life. I am adopting a position that recognises the distress that people experience and considers carefully how to respond. This position is, as I explained in the paper, based on a considerable volume of theory and practice. This is also the position that gets me clearance from research ethics committees for the research that I do. The question I have here for Richard is simple: what does/would he do in the face of emotional reaction, and what theory/evidence does he have that reassures him that his actions are not 'potentially dangerous?

\section{References}

1 Taket A (2002). Facilitation: some contributions to theorising the practice of operational research. $J$ Opl Res Soc 53: $126-136$.

South Bank University,

London, $U K$

A Taket 